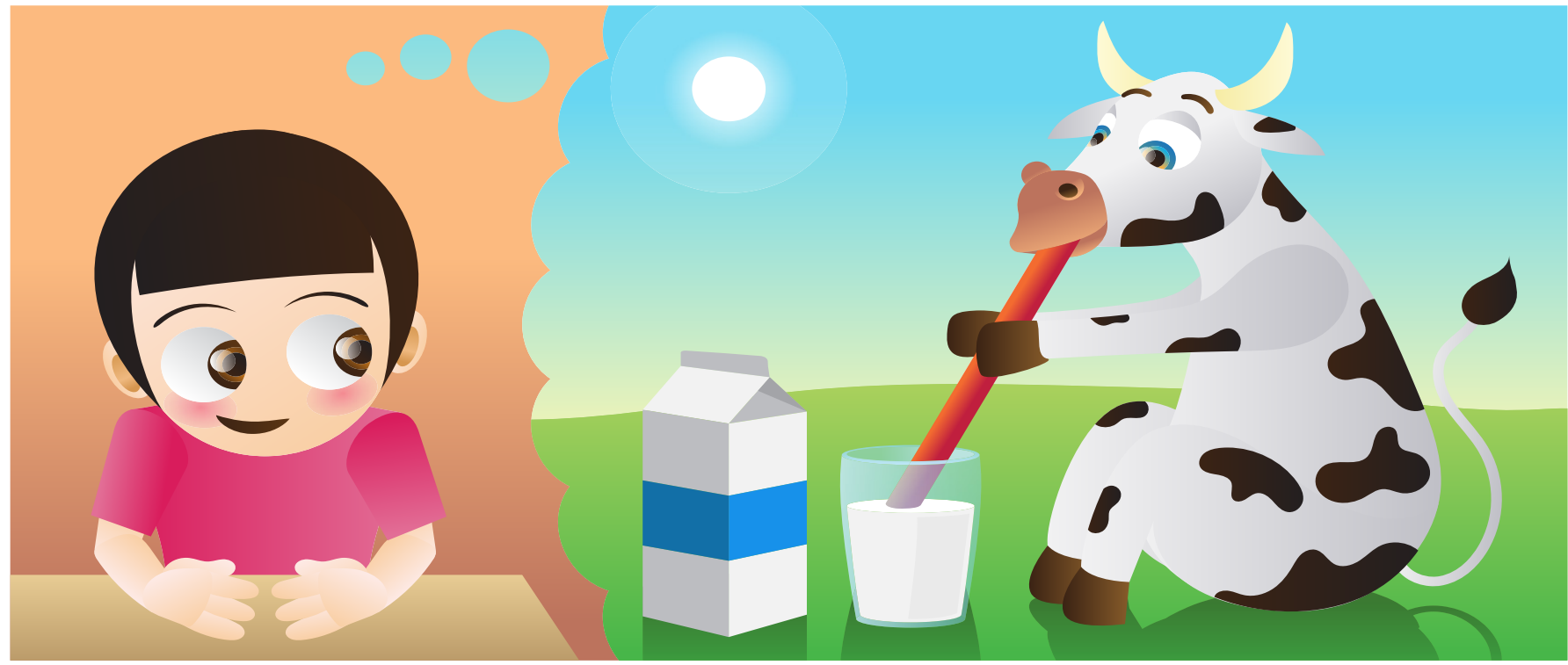

\title{
BLOCKING OUR BRAIN: HOW WE CAN AVOID
}

\section{REPETITIVE MISTAKES!}

\section{Lorie-Marlène Brault Foisy ${ }^{1,2 *}$, Emmanuel Ahr ${ }^{3,4 *}$, Steve Masson ${ }^{1,2}$, Grégoire Borst ${ }^{3,4}$ and Olivier Houdé $3,4,5$}

${ }^{1}$ Département de Didactique, Université du Québec à Montréal, Montréal, QC, Canada, '2Laboratory for Research in Neuroeducation, Montréal, QC, Canada, ${ }^{3}$ Institut de Psychologie, University Paris Descartes, Paris, France, ${ }^{4}$ LaPsyDÉ, CNRS Unit 8240, Paris, France, 5Institut Universitaire de France, Paris, France

\section{REVIEWED BY: \\ JULIEN \\ 12 YEARS OLD}

Persistent mistakes at schools are difficult for teachers, parents, and most of all the children to deal with. Children who keep making the same mistakes tend to be viewed as bad students, but here we propose a different point of view! We think that children often make mistakes not because they do not know the correct answer, but because they fail to block a quicker but wrong answer that seems to make sense. Studies of the brain actually revealed that children, as well as adults, use an area of the brain called the prefrontal cortex to inhibit persistent mistakes. Learning to inhibit these mistakes is thus a promising way to help children overcome difficulties at school as well as to help us think more logically as we face problems in everyday life.

\section{INTRODUCTION}

Have you ever noticed that some mistakes happen more often and seem to be more difficult to prevent than others? For example, answer the following question as fast as you can. Ready? 
What Does the Cow Drink? Your quick answer, like most people, was probably "milk" because of the very strong association between cows and milk, even though you are well aware that cows do not drink milk. Similar mistakes also happen at school. You might even have experienced this without even realizing it. For example, in science, children (and some adults!) often keep believing things that seem true but are actually false. When you were young, you may have thought that the sun was moving in circles around the Earth because you noticed that the sun was moving across the sky from east to west during the day. Your brain treated the sun the same way it treated any other moving objects you observed, and you concluded that the sun was circling around the Earth. Later, you learned that you were wrong, and that it is the Earth (along with all the other planets in our solar system) that is moving around the sun. Even in your English class, you probably made the same mistakes over and over: don't we all tend to leave out the "s" at the end of the verb in sentences like "the vase of flowers make the room look nice"? There sure are many other examples of common mistakes that you, your teachers, or your parents have noticed and wondered how to overcome. You are about to discover what happens in your brain when you make such mistakes and when you overcome them!

\section{WHY DO SOME MISTAKES HAPPEN MORE OFTEN THAN OTHERS?}

In order to answer this question, let us start with an example. In a very famous experiment [1], children are asked whether the two rows of coins presented below contain the same number of coins. You can try it!

\section{FIGURE}

When you try to solve a problem, heuristics "H" and algorithms "A" always race with each other in your brain.

Heuristics are faster! A. When there is no trap, heuristics give the correct answer. B. When there is a trap, heuristics give the wrong answer! Algorithms always provide the correct answer, but they are slower than heuristics.

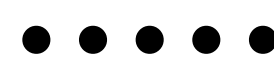

If you let yourself answer quickly, don't you want to say that there are more dots in the upper row? Why? Because in your everyday life, at the library, for instance, when a line of books is longer than another one, it usually contains

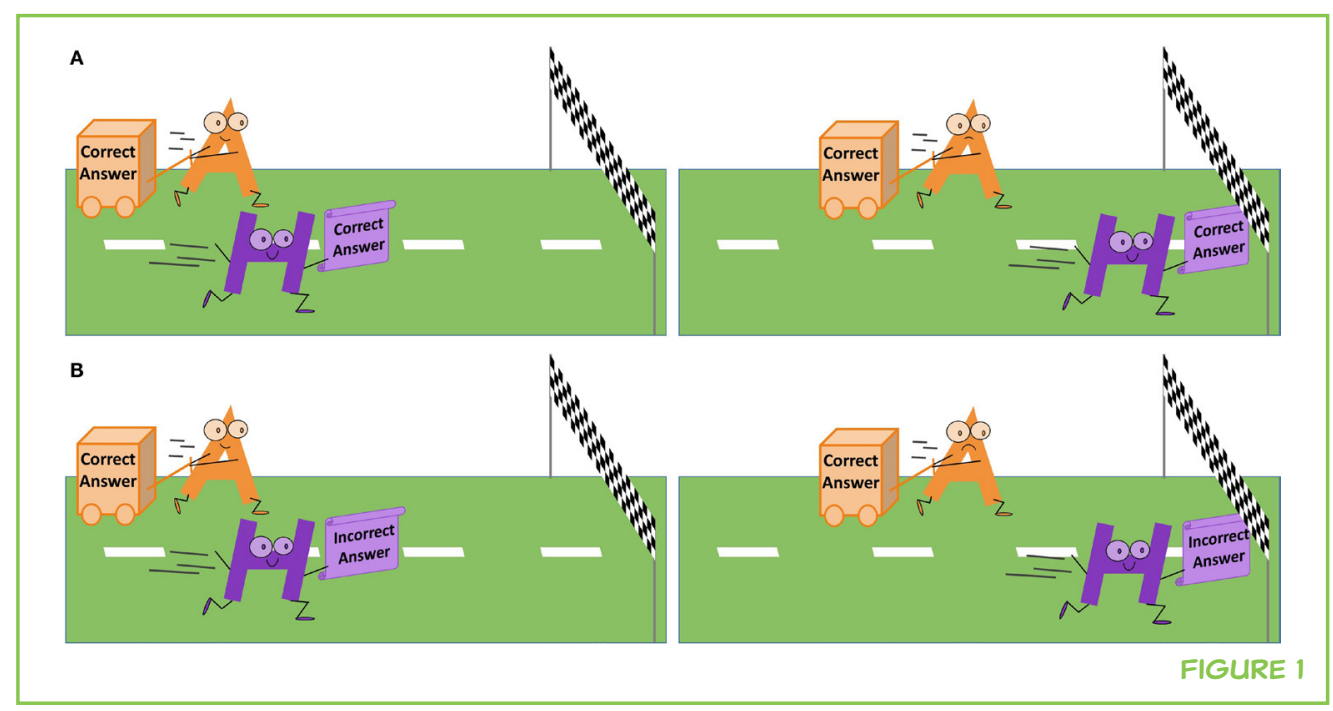


more books. Your brain is very good at picking up on these kinds of patterns in your environment and it will tend to create a "rule," in this case the "length equals number" rule and use this rule every time you need to decide which of two groups contains more items. We call these types of rules made by the brain heuristics. Heuristics are very useful because they are fast, require little effort, and almost always give us the right answer. But not always! For instance, in the experiment presented above, we spontaneously want to use the "length equals number" heuristic, but ... there is a trap! In this specific case, the heuristic gives us the wrong answer. The heuristic does not work here because the gap between the coins is not the same in the two rows. So here, to give the correct answer, you need to actually count the coins in each alignment and determine whether the numbers are the same. We call this type of strategy an algorithm. Algorithms are slower and take more mental effort than heuristics, but they always give us the correct answer. When you face a problem, there is always a race in your brain between heuristics and algorithms. Heuristics almost always win, because they are faster and easier to use. But they are so fast that, when there is a trap, the heuristic makes you fall into it and make mistakes! (see Figure 1 for a typical race between the two.) Here are two other examples of heuristics and algorithms. The heuristic "moving = living" makes you believe that everything that is able to move is alive. But some things move without being alive, such as cars or robots. An algorithm that allows you to accurately recognize living being is, for instance, observing that the thing is born, develops, reproduces, and dies. Another common heuristic is to believe that heavier things will sink and lighter things will float. But a coin is very light and sinks whereas a huge metal navy boat floats! A good algorithm for this would involve taking into account the mass, the shape, and the volume of the object. You will see more examples of heuristics and algorithms in the following sections.

\section{WHAT HAPPENS IN YOUR BRAIN WHEN YOU MANAGE TO AVOID THE TRAP AND PROVIDE THE CORRECT ANSWER?}

To understand how the brain works, researchers use devices such as a magnetic resonance imaging (MRI) scanner, which allows them to measure the areas of the brain that are activated when a person is part of an experiment. If you do not remember how the MRI works, you can read the article entitled "STOP! How we inhibit acts!" by Swann and Greenhouse in Frontiers for Young Minds. Researchers used an MRI scanner to figure out what happens in the brain when an algorithm wins over a heuristic in a tricky problem, like the one below, invented by Professor Stroop. This famous game measures how good people are at preventing the heuristic from winning the race. Want to give the Stroop task a try? See how quickly you can say aloud the name of the ink color the following words are written in. Beware! You must not read the words, but name the ink color! Are you ready? Go!

BLUE RED GREEN BLUE BLUE RED GREEN RED BLUE GREEN 


\section{FIGURE 2}

A. The prefrontal cortex is shown here in purple, at the very front of the head (painting by Morgane Peyou, association

Espace Créativité).

B. Captain Inhibition "l" stops the heuristic "H."

The algorithm "A" eventually gives the correct answer.

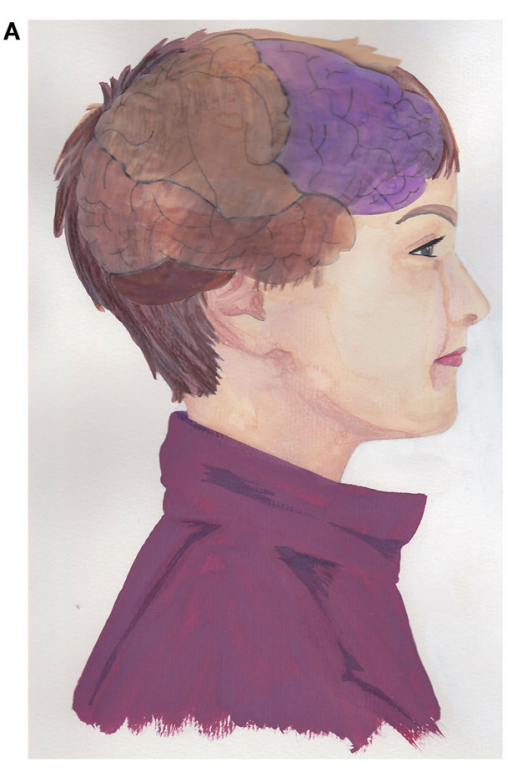

B
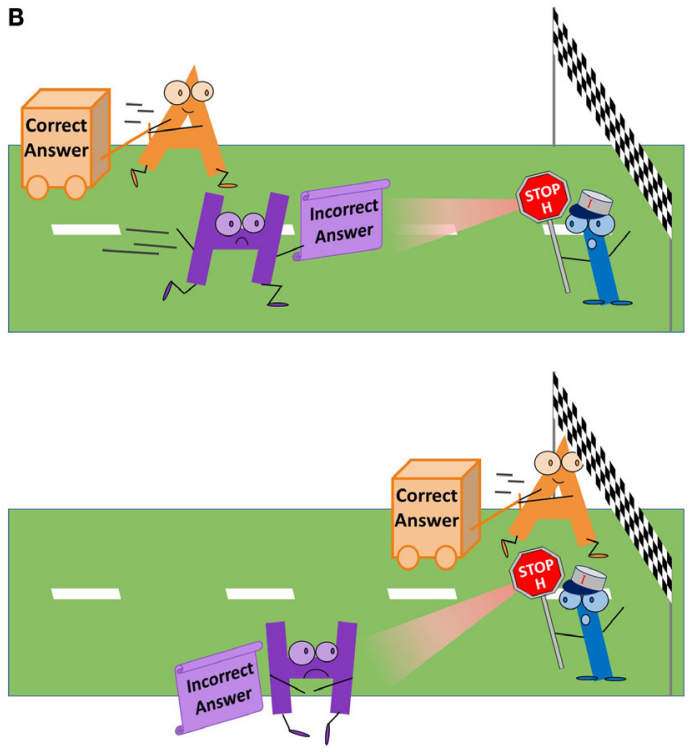

FIGURE 2

Hard, isn't it? Here, the heuristic is to read the word instead of naming the ink color, and it can prevent you from using the algorithm, which is "naming the ink color." But try it several times, and if you concentrate hard enough you will succeed! Did you? Congratulations! Your algorithm won the race over the heuristic!

Using an MRI scanner, scientists found that people use very specific regions of the brain when they play the Stroop task [2] and, in particular, they use the area located in the front of the brain called the prefrontal cortex (colored in purple in Figure 2A). The prefrontal cortex coordinates the work of all the other brain areas, and its role is usually to determine which areas should not be working. So basically, the prefrontal cortex allows us to inhibit (block) the heuristics. As you can see in Figure 2B, this inhibition is the key to resisting the habit of using a heuristic in a tricky problem! [1]. Therefore, this type of inhibition can be very helpful when you need to resist a bad habit, a false belief, or an incorrect strategy. That is why we like to refer to it by using the expression positive inhibition.

To sum up, heuristics are very useful most of the time and you do not need inhibition and costly algorithms in most of the problems you come across each day. But in some specific cases, heuristics give the wrong answer! If you recognize these cases, you can learn to inhibit the tricky heuristic and replace it with an algorithm that will give you the correct answer for sure.

Let us see how inhibition is also important in preventing mistakes at school, in mathematics, reading, and science! 


\section{MATHEMATICS}

Let us start with math! Remember that the experiment in which you needed to determine whether the two rows had the same number of coins? We asked 5- to 10-year-old children to do this experiment while the activity in their brain was measured with an MRI scanner [3]. In all of the children, the researchers found that the areas of the brain that are known to deal with vision and math were activated. But for the children older than 7 who successfully performed the task, an additional area was activated in their brain ... guess which one it was? Yes, it was the prefrontal cortex, the same area that was activated when children did the Stroop task! So, in this experiment, researchers found that if younger children make a mistake, it is not because they are not able to activate the proper visual and mathematical areas of their brain, but mainly because they fail to activate the prefrontal area of their brain in order to inhibit the "length-equals-number" heuristic!

\section{READING}

Now let us see whether we also need prefrontal inhibition from the brain to be good readers. Have you ever mixed up letters like "b" and "d"? You know that these letters are different, but they are mirror images of each other. Here again, a heuristic tricks you: in many cases, your brain sees no difference between mirror images! You can recognize your friend even when you see just the left or just the right side of his face, can't you? This heuristic is a property of the brain called mirror generalization. Unfortunately, because of mirror generalization, it is very hard for your brain to notice the difference between the letters $b$ and $d$, or $p$ and q. So, the question is: do we need inhibition from the prefrontal cortex to overcome these mirror mistakes in reading? We used a special experiment to determine whether inhibition takes place during reading [4]. To make sure you understand how this special experiment works, let us take an example of the Stroop task! Remember that in the Stroop task, you must name the color of the ink without reading the words. Let us try to do this task with two pairs of words.

$\begin{array}{lll}\text { Let's start with this one: } & \text { YELLOW } & \text { BLUE } \\ \text { And now let's try this one: } & \text { RED } & \text { BLUE }\end{array}$

You might have noticed that it took you just a bit more time to say that the word BLUE was written in red in the second pair than in the first one. This is because in the second pair you must activate the color red, which you just inhibited when you looked at the first word (RED) to say that the ink color was green! Inhibition slows down a following activation!

We used this same idea to study whether our brains need to inhibit mirror generalization. If so, then the inhibition of mirror generalization when we distinguish between $b$ and $d$ will slow down the activation of mirror generalization just after. To activate the mirror-generalization heuristic, we asked participants to say that a horse presented from the right side is the same as its mirror image, which is this same horse presented from the left side 


\section{FIGURE 3}

Examples of the images presented to the participants.

The presentation of the two letters was followed by the presentation of the two animals. Example A. shows two different letters that are not mirror images of each other ("f" and " $\mathrm{t}$ ") followed by two horses facing opposite directions. Example B. shows two mirror letters ("b" and "d") followed by two horses facing opposite directions. Adult readers needed more time to answer that the animals were the same (i.e., to activate mirror generalization) in example B. than in example A. So, they must have inhibited mirror generalization just before to answer that the mirror letters "b" and "d" were different. There is no need to inhibit mirror generalization for " $\mathrm{f}$ " and "t" as they are not mirror letters.

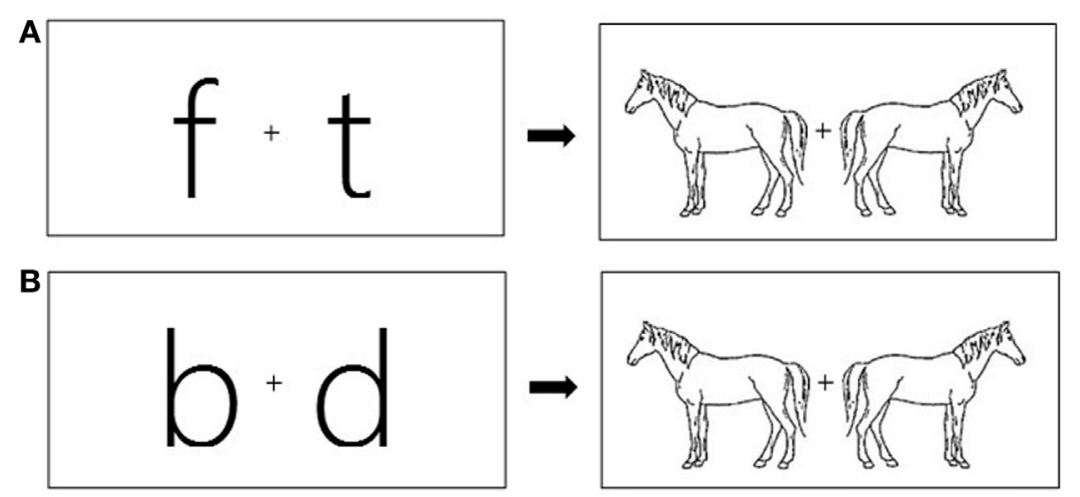

FIGURE 3

(see Figure 3). Eventually, participants had to discriminate between two mirror letters like $\mathrm{b}$ and $\mathrm{d}$ (so they supposedly inhibit mirror generalization), then between two animals (so they activate mirror generalization). We found that even good readers were indeed slower to activate mirror generalization after having correctly answered that $\mathrm{b}$ is different for $\mathrm{d}$, or $\mathrm{p}$ from $\mathrm{q}$, in comparison with a situation where they did not previously inhibit mirror generalization (i.e., we showed them letters with no mirror image counterpart like $\mathrm{f}$ and $\mathrm{t}$ ).

Once you become a good reader, you inhibit the mirror-generalization heuristic when you see mirror letters without even thinking about it. To tell the letters apart, you also automatically activate the algorithm "taking the orientation into account." That means that you can train your brain to inhibit and replace a heuristic with an algorithm so quickly that it becomes automatic!

\section{SCIENCE}

Believe it or not, adults also make persistent mistakes! Let us look at an example in science this time. Imagine this situation: you have a small lead ball in one hand and a big one in the other hand. They are both a bit heavy, but you can feel that the big one is significantly heavier than the small one. Now, answer this question: if you drop the two balls from the same height at the same moment, which one will hit the ground first? Also, ask your parents what they think! This is a tricky question. Most people will say that the bigger, heavier ball will hit the ground before the smaller, lighter one, but that is not the right answer. Surprisingly, both balls will actually touch the ground at the same time! You can find the complete scientific explanation here (https://www.youtube.com/ watch? $\left.v=\_m C C-68 L y Z M\right)$. You can try this at home - try dropping a bottle full of water at the same time as an empty one!

Recently, expert and non-expert scientists were asked to answer this exact same question while the activity of their brain was measured with an MRI scanner [5]. As expected, non-expert scientists thought that the heavier ball would touch the ground first, whereas expert scientists gave the correct answer. What allowed experts to avoid falling into the trap? Well, one additional brain area was activated in expert scientists. Guess which one! Yes, the prefrontal cortex, 
the area that inhibits heuristic strategies, just as we saw earlier in the example with the children who looked at the two rows of coins! So, even expert adults must learn to inhibit heuristics and do so all the time in order to avoid making these kinds of mistakes!

The question you might be asking yourself at this point is: Can I improve my inhibitory skills? And, if so, how can I become Captain Inhibition?

\section{HOW CAN WE IMPROVE OUR INHIBITORY SKILLS?}

From reading this article and learning more about positive inhibition, you might have realized one really important thing: our brains continuously adapt and improve as we learn. This characteristic is called neuroplasticity (for more information about neuroplasticity, read the article entitled "Going to School to Sculpt the Brain" by Javier DeFelipe in Frontiers for Young Minds). When you learn, some connections between different parts of your brain change as you become an expert in things like reading, math, or inhibition! So, it makes sense that you can improve your inhibitory skills and the functioning of your prefrontal cortex through learning, but how?

Well, for now, becoming Captain Inhibition might be an ambitious challenge! We know that it is possible, but we do not know exactly how to do so. In studies at a research laboratory called LaPsyDÉ in Paris, some elementary school-age children took part in an experiment where they were trained to be super careful when solving tricky problems by identifying and inhibiting heuristics. Compared to other children who did not receive this training, the children who did were able to give more correct answers to tricky problems! These results tell us that your brain can actually learn to be a better inhibitor! And if you become good at inhibiting heuristics in tricky contexts, your brain will be able to replace heuristic answers with algorithmic answers that will give you the correct answer for sure. So now, when you repeat the same mistakes several times, don't give up! What you must do is ask your teacher to help you find and understand the heuristic you spontaneously use, then practice inhibiting it many times!

\section{REFERENCES}

1. Houdé, O., and Borst, G. 2014. Measuring inhibitory control in children and adults: brain imaging and mental chronometry. Front. Psychol. 5:616. doi:10.3389/ fpsyg.2014.00616.

2. Adleman, N. E., Menon, V., Blasey, C. M., White, C. D., Warsofsky, I. S., Glover, G. H., et al. 2002. A developmental fMRI study of the Stroop color-word task. Neuroimage 16(1):61-75. doi:10.1006/nimg.2001.1046.

3. Houdé, O., Pineau, A., Leroux, G., Poirel, N., Perchey, G., Lanoë, C., et al. 2011. Functional MRI study of Piaget's conservation-of-number task in preschool and 
school-age children: a neo-Piagetian approach. J. Exp. Child Psychol. 110:332-346. doi:10.1016/j.jecp.2011.04.008.

4. Borst, G., Ahr, E., Roell, M., and Houdé, O. 2015. The cost of blocking the mirrorgeneralization process in reading: evidence for the role of inhibitory control in discriminating letters with lateral mirror-image counterparts. Psychon. Bull. Rev. 22:228-234. doi:10.3758/s13423-014-0663-9.

5. Brault Foisy, L.-M., Masson, S., Potvin, P., and Riopel, M. 2015. Is inhibition involved in overcoming a common physics misconception in mechanics? Trends. Neurosci. Educ. 4:26-36. doi:10.1016/j.tine.2015.03.001.

SUBMITTED: 25 August 2015; ACCEPTED: 26 November 2015; PUBLISHED ONLINE: 14 December 2015.

EDITED BY: Silvia A. Bunge, University of California, Berkeley, USA

CITATION: Brault Foisy L, Ahr E, Masson S, Borst G and Houdé O (2015) Blocking Our Brain: How We Can Avoid Repetitive Mistakes!. Front. Young Minds 3:17. doi:10.3389/ frym.2015.00017

COPYRIGHT @ 2015 Brault Foisy, Ahr, Masson, Borst and Houdé. This is an open-access article distributed under the terms of the Creative Commons Attribution License (CC BY). The use, distribution and reproduction in other forums is permitted, provided the original author(s) or licensor are credited and that the original publication in this journal is cited, in accordance with accepted academic practice. No use, distribution or reproduction is permitted which does not comply with these terms.

\section{REVIEWED BY:}

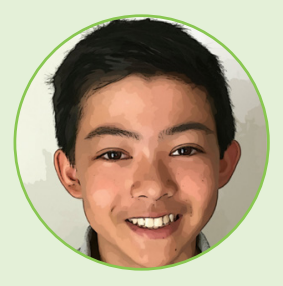

\section{JULIEN, 12 YEARS OLD}

Hello, my name is Julien and I am a 7th grader. I was born in California and still live there. My favorite subjects are math, science, history, language arts, and technology. My interests include guitar, violin, piano, and taekwondo. I enjoy reading and writing. I am involved in cross-country. I also started rock climbing when I was 5 !

\section{AUTHORS}

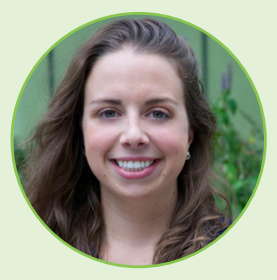

\section{LORIE-MARLÈNE BRAULT FOISY}

A PhD student at the University of Quebec in Montreal (UQAM). After studying, I become a teacher in elementary school, I decided that I wanted to know more about how children learn. This is why I am doing research in education. I think it is important to understand better what happens in the brain of children when they learn different things (e.g., reading, science). If we understand better how their brain learn, we can eventually know how to teach them better! In my spare time, I personally like to read a lot. I also enjoy going to museums, traveling and spending time with my family! L-MF contributed equally with EA. 


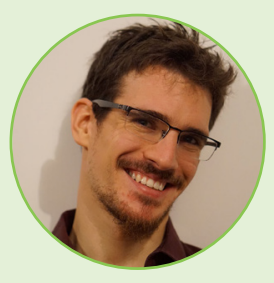

\section{EMMANUEL AHR}

Emmanuel Ahr deeply trust in education. With a good education, you can make the best choices to improve your life and the world. But as a schoolboy, I found it so hard to understand how I can be an efficient learner! So, I decided to study learning mechanisms with cognitive and educational sciences, and I became a PhD student at the Laboratory for the Psychology of Child Development and Education in Paris. Outside the lab, I like teaching and talking with friends for hours! L-MF contributed equally with EA.

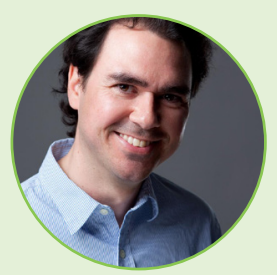

\section{STEVE MASSON}

A professor at Université du Québec à Montréal. Using a tool called magnetic resonance imaging, I look inside the brain to see what changes when students learn in school. Sometimes, I even look if the way teachers teach influences what change in students' brain when they learn. Pretty cool!

\section{GRÉGOIRE BORST}

A Professor of developmental psychology and cognitive neuroscience of education in the LaPsyDE. My research focuses on the role of Captain Inhibition in the cognitive and brain development of children, adolescent, and young adults. Recently, I also started to see how Captain Inhibition helps children and young adults to overcome systematic difficulties at school and in the University. In my spare time, I enjoy reading books, cooking, and playing games with my two kids.

\section{OLIVIER HOUDÉ}

I am the Director of the LaPsyDÉ and Professor at the Sorbonne in Paris, France. A few years ago, using brain imaging, I have discovered the role of Captain Inhibition in the brain of children. Now, all the laboratory is working on this process and I am very happy about it ! I also wrote a lot of books in French on Captain Inhibition and child psychology. In my spare time, I enjoy painting. 